\title{
MICROWAVE ENHANCED CHROMIUM EXTRACTION FROM SEWAGE SLUDGE AND SOIL-SLUDGE MIXTURES USING BIODEGRADABLE CHELANTS
}

Valdas PAULAUSKAS, Department of Environment and Ecology, Agriculture Academy, Vytautas Magnus University, K. Donelaičio g. 58, 44248 Kaunas Lithuania, valdas.paulauskas@ vdu.lt (corresponding author)

Ernestas ZALECKAS, Department of Agricultural Engineering and Safety, Agriculture Academy, Vytautas Magnus University. K. Donelaičio g. 58, 44248 Kaunas Lithuania, ernestas.zaleckas@ vdu.lt

Dovilè TUMOSAITÉ, Agriculture Academy, Vytautas Magnus University, K. Donelaičio g. 58, 44248 Kaunas Lithuania, dovile.tumosaite@vdu.lt

\begin{abstract}
Microwave enhanced chromium extraction from sewage sludge and soil-sludge mixtures was carried out using ethylenediaminetetraacetic acid (EDTA) and more biodegradable chelating agents: methyleneglycinediacetic acid (MGDA), S, S'-ethylenediaminedisuccinic acid (EDDS) and S-carboxyl-Lcysteine (SCLC). Raising the temperature using microwave energy had particularly strong effect on Cr extraction efficiency with MGDA from all the investigated biosolids. The higher was the temperature, the larger amount of metal was extracted - maximum removal efficiency with MGDA at $150^{\circ} \mathrm{C}$ was 38 times higher than that at $20^{\circ} \mathrm{C}$. The effect of microwave-assisted extraction duration was also significant - extraction effectiveness increased by $40-60 \%$ at $150^{\circ} \mathrm{C}$ while increasing duration from $15 \mathrm{~min}$ up to $60 \mathrm{~min}$, depending upon the type of biosolid tested. MW-enhanced chromium extraction efficiency from sludge mixture with clay soil was in all cases significantly lower than that from the raw sludge samples as well as sludge mixture with sandy soil. Extraction study showed that such readily degradable agents as EDDS and MGDA can be successfully used to wash biosolids in the presence of chromium contamination instead of persistent EDTA when microwave energy is applied, while SCLC was less efficient. According to the complexation efficiency, the investigated chelants can be ranked in the following order: EDTA $\approx$ MGDA $>$ EDDS $>$ SCLC, while the overall chromium removal capacity of MGDA was better than that of EDDS
\end{abstract}

Keywords: Chromium, Sewage sludge, Microwave-Enhanced Extraction, Biodegradable Chelants

\section{INTRODUCTION}

Sewage sludge (S) is the final residue from wastewater treatment plants (WTPs) generated during the process of municipal wastewater treatment. It has been shown that sewage sludge on-land application improves physical, chemical as well as biological properties of the soil. Sludge can be a valuable source of primary plant nutrients (such as nitrogen and phosphorus) as well as secondary nutrients (sulphur, calcium, magnesium), also can act as an effective soil conditioner because of high organic matter content (Ashekuzzaman et.al., 2019; Feasibility study.., 2018; Dargenis et al., 2008; Epstein, 2003). According to the National Waste Management Plan of the Republic of Lithuania (State plan.., 2014) onland sewage sludge recycling is a preferred solution rather than sludge disposal in the municipal landfills or special longterm sludge storage facilities. However, safe sewage sludge utilisation is often limited by elevated concentration of heavy metals (HM), which can give rise to accumulation of these potentially toxic elements in the topsoil, following adverse effects on plant growth and crop quality (Alloway, 2013). Moreover, wastewater sludge on-land application poses a great concern because soil acts as a transferor, and due to bioaccumulation HM can appear in a food chain (Praspaliauskas \& Pedišius, 2017; Kabata-Pendias, 2011; Emmerich et al., 1982).

Negative impact of HM on the environment and human health can be effectively reduced by removing them from $\mathrm{S}$ or soil-sludge mixtures. A number of different extracting agents were applied for chemical heavy metal extraction from the solids: aqueous solutions of organic and inorganic acids, their salts, oxidizing or reducing chemicals, also various metal complexing agents (Navarro-Gonzalez et al., 2017; Suanon et al., 2016; Bolan et al., 2014; Komarek et al., 2007; Zaleckas et al., 2007; Yuan et al., 2007; Zhang et al., 2006; Moutsatsou et al., 2006; Khodadoust et al., 2005; Marchioretto et al., 2002; Labanowski et al., 2007). Divalent ions of heavy metals such as copper $\left(\mathrm{Cu}^{2+}\right)$, zinc $\left(\mathrm{Zn}^{2+}\right)$, nickel $\left(\mathrm{Ni}^{2+}\right)$, lead $\left(\mathrm{Pb}^{2+}\right)$, cadmium $\left(\mathrm{Cd}^{2+}\right)$ or chromium $\left(\mathrm{Cr}^{2+}\right.$ as well as $\left.\mathrm{Cr}^{3+}\right)$ will form coordination compounds with electron-donating nitrogen $(\mathrm{N})$ or oxygen $(\mathrm{O})$ atoms in the presence of polycarboxyamino acids. Ethylenediaminetetraacetic acid (EDTA) exhibits high effectiveness in the separation of metals from the biosolids, but because of its low biodegradation rate following high persistence in the environment it is to be replaced with other more rapidly decomposing and environment more friendly chelate forming extractants (Suanon et al., 2016; Renella et al., 2004; Ritschel, 2003; Grcman et al., 2003;

Copyright (C) 2021 The Authors. Published by Vytautas Magnus University. This is an open-access article distributed under the terms of the Creative Commons Attribution License (CC BY 4.0), which permits unrestricted use, distribution, and reproduction in any medium, provided the original author and source are credited. 


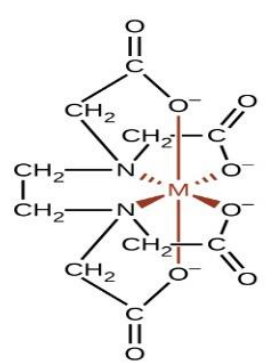

Figure 1. The typical chelate-type structure of EDTA-M (Metal) hexadentate complexes (Khairia, 2017)

Bucheli and Egli; 2001; Takahashi et al., 1997). The ligand EDTA binds tightly to a variety of metal ions by forming hexadentate complexes (Fig. 1).

Similar EDTA-type chelants can form stable and at the same time highly soluble complexes with the transition elements due to hexadentate ligand and $\mathrm{M}$ (Metal) bonding through nitrogen and oxygen atoms - donor atoms with unshared electron pairs which can coordinate a metal ion (Khairia, 2017; Dupare, 2015). They can show high effectiveness in the removal of HM from contaminated water as well as solids. The importance of these ligands as chelating agents in the field of environmental technology supports the need for an exploration of their effectiveness in different conditions.

The objective of the present study was to evaluate the efficiency of more than EDTA biodegradable chelating agents used for the microwave enhanced removal of chromium $(\mathrm{Cr})$ from sludge and soil-sludge mixtures at a different temperature range $\left(50,100,150^{\circ} \mathrm{C}\right)$ and extraction duration (15 and $60 \mathrm{~min}$ ).

\section{RESEARCH METHODS}

Anaerobically digested sewage sludge was sampled at Kaunas WTP after sludge dewatering. Sludge was brought back to the laboratory, dried at $40^{\circ} \mathrm{C}$ and ground in a ball-mill, soil was air-dried, sieved to pass a $2 \mathrm{~mm}$ mesh screen, homogenized thoroughly and later two different sludge-soil mixtures were prepared: sludge with clay soil and sludge with sandy soil. Chelant-induced chromium removal experiment was carried out with strong metal chelating compounds (chelants) - the selected organic di-, tri- and tetra-carboxy amino acids: S-carboxyl-L-cysteine (SCLC), methyleneglycinediacetic acid (MGDA), ethylenediaminetetraacetic acid (EDTA) and S, S'-ethylenediaminedisuccinic acid (EDDS) and (Table 1).

Table 1. Chemical structure of chelating agents (polycarboxyamino acids) used as extractants for chromium removal from sludge based biosolids

\begin{tabular}{|c|c|c|c|}
\hline Extracting agent & $\begin{array}{c}\text { Number of } \\
\text { functional } \\
\text { carboxygroups }\end{array}$ & Abbreviation & Chemical structure \\
\hline $\begin{array}{l}\text { Methyleneglycinediacetic } \\
\text { acid }\end{array}$ & Tricarboxylic- & MGDA & $\mathrm{HO}$ \\
\hline $\begin{array}{l}\text { Ethylenediaminetetraacetic } \\
\text { acid }\end{array}$ & Tetracarboxylic- & EDTA & $\begin{array}{l}\text { HOOC } \\
\text { HOOC }\end{array}$ \\
\hline $\begin{array}{c}\text { S, S'- } \\
\text { ethylenediaminedisuccinic } \\
\text { acid }\end{array}$ & Tetracarboxylic- & EDDS & $\underset{\text { HOOC }}{\mathrm{HOOC} \longrightarrow}$ \\
\hline S-carboxyl-L-cysteine & Dicarboxylic- & SCLC & \\
\hline
\end{tabular}

Removal tests were performed following steps provided in Figure 2 with S and two different sludge-soil mixtures: sludge mixture with clay soil (S-CS) and sludge mixture with sandy soil (S-SS). Sewage sludge (S) and soil (CS or SS) ratio in the mixtures was 1:1 on a dry weight basis. All chelating agents were used as $0.1 \mathrm{M}$ aqueous solutions, the $\mathrm{pH}$ was settled using $\mathrm{NaOH}$ or $\mathrm{HNO}_{3}$, and extraction was performed at a liquid/solid ratio $-10: 1$ and room temperature $\left(20^{\circ} \mathrm{C}\right)$. Microwave-assisted HM extraction (at temperatures - 50, 100 and $150^{\circ} \mathrm{C}$ ) was performed in the microwave (MW) oven A MLS-ETHOS (Leutkirch, Germany). Microwave-enhanced extraction duration was 15 and $60 \mathrm{~min}$.

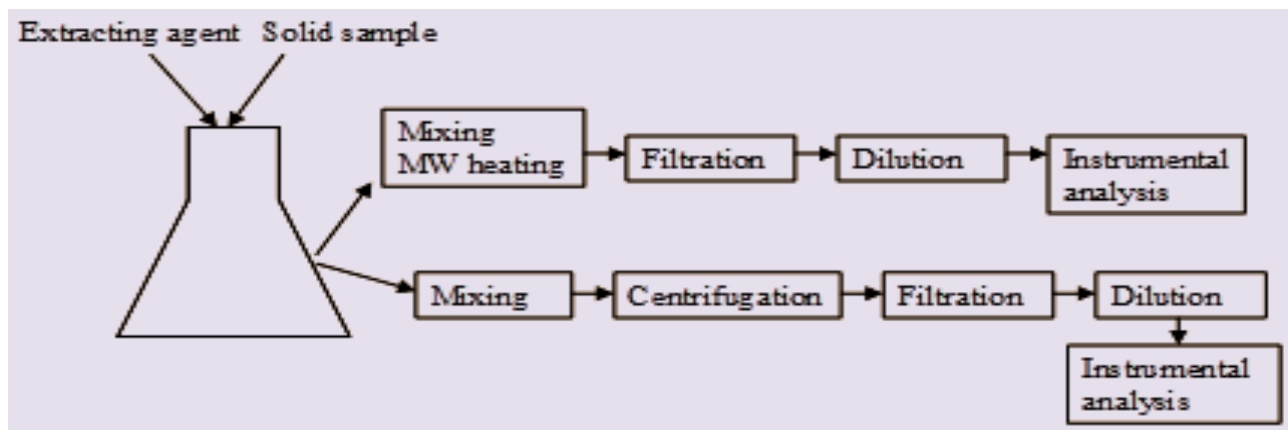

Figure 2. Main steps of microwave and batch experiments of chromium removal from sludge and sludge-soil mixtures

After extraction followed 25 min ventilation period, then solution was filtered and chromium (as well as other $\mathrm{HM}$ ) concentration in the solutions has been determined by atomic absorption spectroscopy (AAS) following the 
requirements given in standard procedures LST EN 13650:2006, LST EN ISO 15586:2004 and LST ISO 8288:2002. All extractions were performed at least in triplicate; average, standard deviation and significance level was calculated using t-test when $\mathrm{p}<0.05$. Calibration using standard solutions was performed before the instrumental analysis.

\section{RESEARCH RESULTS}

Though being highly effective in metal removal processes, application of EDTA, due to its slow biodegradation, can greatly increase bioavailability of toxic metals in the soil environment after remediation (Cao et al., 2008; Labanowski et al., 2007). Moreover, it can be the cause of groundwater and surface water pollution by heavy metal compounds that have become much more mobile (Sun et al., 2001; Takahashi et al., 1997; Schowanek et al., 1997). Therefore, comparable extraction tests were performed using other more biodegradable (Paulauskas et al., 2019; Renella et al., 2004) than EDTA polycarboxy amino acids: EDDS, MGDA and SCLC.

Results showed (Fig. 3) that raising the temperature using microwave energy had particularly strong effect on $\mathrm{Cr}$ extraction efficiency with MGDA from all the investigated biosolids. The higher was the temperature, the larger amount of metal was extracted - Cr extraction efficiency (EE) from the sludge at $150^{\circ} \mathrm{C}$ after $1 \mathrm{~h}$ mixing was above $60 \%$, while at $20-50^{\circ} \mathrm{C} \mathrm{EE}$ did not exceed $10 \%$, and maximum removal efficiency with MGDA at $150^{\circ} \mathrm{C}$ was 38 times higher than that at $20^{\circ} \mathrm{C}$. The effect of microwave-assisted extraction duration was also significant - extraction effectiveness increased by $40-60 \%$ at $150^{\circ} \mathrm{C}$ while increasing duration from $15 \mathrm{~min}$ up to $60 \mathrm{~min}$, depending upon the type of biosolid tested. MW-enhanced chromium extraction efficiency from sludge mixture with clay soil was in all cases significantly lower than that from the raw sludge samples as well as sludge mixture with sandy soil.

Extraction study showed that such readily degradable agents as EDDS and MGDA can be successfully used to wash biosolids in the presence of chromium contamination instead of persistent EDTA when microwave energy is applied, while SCLC was less efficient. According to the complexation efficiency, the investigated chelants can be ranked in the following order: $\mathrm{EDTA} \approx \mathrm{MGDA}>\mathrm{EDDS}>$ SCLC.

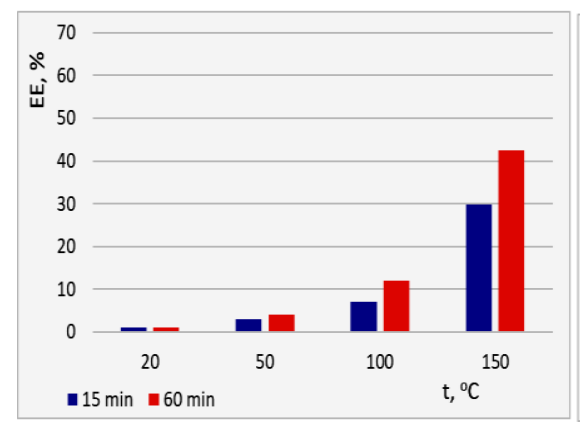

a

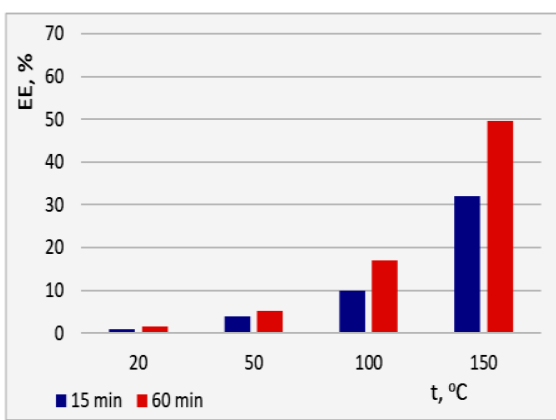

b

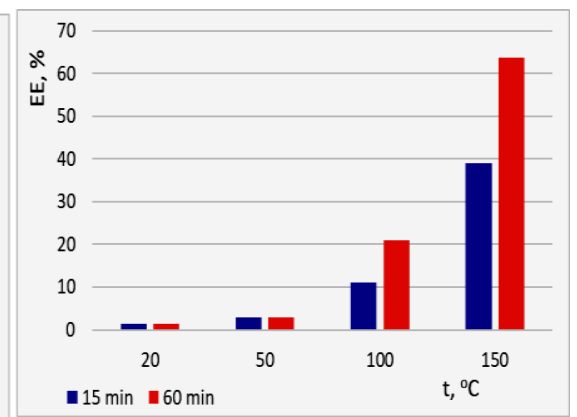

$\mathrm{c}$

Figure 3. Microwave-enhanced $\mathrm{Cr}$ extraction efficiency after 15 and 60 min treatment at different temperature $\left(20,50,100\right.$ and $\left.150^{\circ} \mathrm{C}\right)$

from the following biosolids: a - S-CS, b-S-SS, c- S (extraction with 0.1M MGDA solution, pH 6, solid: solution ratio - 1:10)

The ranking order of the heavy metals according to the summarised extraction efficiency at room temperate was following: $\mathrm{Zn}>\mathrm{Ni} \geq \mathrm{Cd}>\mathrm{Cu} \geq \mathrm{Pb}>>\mathrm{Cr}$ (Table 2). Overall $\mathrm{HM}$ removal capacity of EDDS was better than that of MGDA in all cases, except for chromium, presumably due to different Me-chelate structure as well as their solubility and stability. Generally, microwave assisted maximum extraction values were in all cases significantly higher, than the best EE result achieved in batch-washing at room temperature (Table 2).

Table 2. Maximum chromium extraction efficiency achieved at a given temperature and compared with the EE of other heavy metals

\begin{tabular}{|c|c|c|c|}
\hline Chelating agent & Heavy metal & $\begin{array}{c}\text { Max extraction efficiency, \% } \\
\left.\text { (temperature at which max EE was achieved, }{ }^{\circ} \mathrm{C}\right)\end{array}$ & Extraction efficiency at $20^{\circ} \mathrm{C}, \%$ \\
\hline \multirow{4}{*}{ MGDA } & $\mathbf{C r}$ & $\mathbf{6 4 . 0}(\mathbf{1 5 0})$ & $\mathbf{1 . 7}$ \\
\cline { 2 - 4 } & $\mathrm{Cd}$ & $34.1(100)$ & 24.7 \\
\cline { 2 - 4 } & $\mathrm{Ni}$ & $57.6(100)$ & 25.9 \\
\cline { 2 - 4 } & $\mathrm{Pb}$ & $24.8(100)$ & 22.2 \\
\cline { 2 - 4 } & $\mathrm{Cu}$ & $12.6(50)$ & 47.4 \\
\cline { 2 - 4 } & $\mathrm{Zn}$ & $86.6(100)$ & \\
\hline
\end{tabular}

Results showed that according to their highest EE from the sewage sludge applying MGDA heavy metals can be ranked in the following order: $\mathrm{Zn}>\mathrm{Cr}>\mathrm{Ni}>\mathrm{Cd}>\mathrm{Pb}>\mathrm{Cu}$. It should be noted, that $\mathrm{HM}$ ranking order at room temperature was quite different.

\section{CONCLUSIONS}

- Raising the temperature using microwave energy had particularly strong effect on Cr extraction efficiency with MGDA from all the investigated biosolids. The higher was the temperature, the larger amount of metal was extracted - 
$\mathrm{Cr}$ EE from the sludge at $150^{\circ} \mathrm{C}$ after $1 \mathrm{~h}$ mixing was above $60 \%$, while at $20-50^{\circ} \mathrm{C} \mathrm{EE}$ did not exceed $10 \%$, and maximum removal efficiency with MGDA at $150^{\circ} \mathrm{C}$ was 38 times higher than that at $20^{\circ} \mathrm{C}$.

- The effect of microwave-assisted extraction duration was also significant - extraction effectiveness increased by $40-60 \%$ at $150^{\circ} \mathrm{C}$ while increasing duration from $15 \mathrm{~min}$ up to $60 \mathrm{~min}$, depending upon the type of biosolid tested.

- MW-enhanced chromium extraction efficiency from sludge mixture with clay soil was in all cases significantly lower than that from the raw sludge samples as well as sludge mixture with sandy soil.

- Extraction study showed that such readily degradable agents as EDDS and MGDA can be successfully used to wash biosolids in the presence of chromium contamination instead of persistent EDTA when microwave energy is applied, while SCLC was less efficient. According to the complexation efficiency, the investigated chelants can be ranked in the following order: $\mathrm{EDTA} \approx \mathrm{MGDA}>\mathrm{EDDS}>\mathrm{SCLC}$. The overall chromium removal capacity of MGDA was better than that of EDDS.

- According to their highest EE from the sewage sludge applying MGDA heavy metals can be ranked in the following order: $\mathrm{Zn}>\mathrm{Cr}>\mathrm{Ni}>\mathrm{Cd}>\mathrm{Pb}>\mathrm{Cu}$. It should be noted, that $\mathrm{HM}$ ranking order at room temperature was quite different $-\mathrm{Zn}>\mathrm{Ni} \geq \mathrm{Cd}>\mathrm{Cu} \geq \mathrm{Pb}>>\mathrm{Cr}$.

\section{REFERENCES}

1. Alloway B. J. (ed.) 2013. Heavy metals in soils. Trace metals and metalloids in soils and their bioavailability. Dordrecht: Springer Science + Business Media. https://doi.org/10.1007/978-94-007-4470-7_2

2. Ashekuzzaman S., Forrestal P., Richards K., Fenton O. 2019. Dairy industry derived wastewater treatment sludge: generation, type and characterization of nutrients and metals for agricultural reuse. Journal of Cleaner Production, Vol. 230, $1266-1275$. https://doi.org/10.1016/j.jclepro.2019.05.025

3. Bolan N., Kunhikrishnan A., Thangarajan R., Kumpiene J., Park. J., Makino T., Kirkham M. B., Scheckel K. 2014. Remediation of heavy metal(oid) contaminated soils - To mobilize or to immobilize? Journal of Hazardous Materials, Vol. 266, pp. 141-166. https://doi.org/10.1016/j.jhazmat.2013.12.018

4. Bucheli-Witschel M., Egli T. 2001. Environmental fate and microbial degradation of aminopolycarboxylic acids. FEMS Microbiology Reviews, Vol. 25, pp. 69-106. https://doi.org/10.1111/j.1574-6976.2001.tb00572.x

5. Cao A., Zappai G., Carucci A., Lai T. 2008. Heavy metal bioavailability and chelate mobilization efficiency in an assisted phytoextraction process. Environmental Geochemistry and Health, Vol. 30. Iss. 2., pp. 115-119. https://doi.org/10.1007/s10653$\underline{008-9136-2}$

6. Dargenis E., Kusta A, Žibas A. 2008. Assessment of sludge treatment possibilities in sewage treatment plants. Vagos, No. 78(31), pp. 77-82. (In Lithuanian).

7. Dupare D. B. 2015. Detection of heavy metal ions from water using conventional chelating agents (Citric Acid and EDTA) in and around Murtizapur Region. International Journal of Chemical and Physical Sciences, Vol. 4, pp. 30-37.

8. Emmerich W. E., Lund,J. L., Page,A. L., Chang A. C. 1982. Solid phase form of heavy metal in sewage sludge in sewage sludge treated soils. Journal of Environmental Quality, Vol. 11, pp. 178-181. https://doi.org/10.2134/jeq1982.00472425001100020007x

9. Epstein E. 2003. Land applications of sewage sludge and biosolids. New York: Lewis Publishers. https://doi.org/10.1201/9781420032116

10. Feasibility study for treatment of old sludge from municipal wastewater treatment and storage sites. 2018. Final report. Book I. In Lithuanian. Sweco Lietuva UAB, $181 \mathrm{p}$.

11. Grcman, H., Vodnik, D., Velikonja-Bolta, S., Lestan D. 2003. Ethylenediaminedissuccinate as a new chelate for environmentally safe enhanced lead phytoextraction. Journal of Environmental Quality, Vol. 32, pp. 500-506. https://doi.org/10.2134/jeq2003.5000

12. Kabata-Pendias A. 2011. Trace elements in soils and plants. Boca Raton: Taylor \& Francis Group. https://doi.org/10.1201/b10158

13. Khairia M. A. A. 2017. Extraction of heavy metals from contaminated water using chelating agents. Oriental Journal of Chemistry, Vol. 33, No. (4), pp. 1698-1704. https://doi.org/10.13005/ojc/330414

14. Khodadoust A. P., Reddy K. R., Maturi K. 2005. Effect of different extraction agents on metal and organic contaminant removal from a field soil. Journal of Hazardous Materials, Vol. 117, Iss. 1, pp. 15-24. https://doi.org/10.1016/i.jhazmat.2004.05.021

15. Komarek M., Tlustos P., Szakova J., Chrastny V., Ettler V. 2007. The use of maize and poplar in chelant-enhanced phytoextraction of lead from contaminated agricultural soils. Chemosphere, Vol. 67, pp. 640-651. https://doi.org/10.1016/j.chemosphere.2006.11.010

16. Labanowski J., Monna F., Bermond A., Cambier P., Fernandez C., Lamy I., van Oort F. 2007. Kinetic extractions to assess mobilization of $\mathrm{Zn}, \mathrm{Pb}, \mathrm{Cu}$, and $\mathrm{Cd}$ in a metal-contaminated soil: EDTA vs. citrate. Environmental Pollution, Vol. 152, 693-701. https://doi.org/10.1016/j.envpol.2007.06.054

17. Marchioretto M.M., Bruning H., Loan N.T.P., Rulkens W.H. 2002. Heavy metal extraction from anaerobically digested sludge. Water Science and Technology, Vol. 46 (10), pp. 1-8. https://doi.org/10.2166/wst.2002.0275

18. Moutsatsou A., Gregou M., Matsas D., Protonotarios,V. 2006. Washing as a remediation technology applicable in soils heavily polluted by mining-metallurgical activities. Chemosphere, Vol. 63, pp. 1632-1640. https://doi.org/10.1016/j.chemosphere.2005.10.015

19. Navarro-Gonzalez M., Ortega-Lopez,V., Lopez-Fernandez,J., Amo-Salas,M., Gonzalez-Carcedo,S. 2017. Heavy-metal extraction from sewage sludge using phosphorous-based salts: optimization process with $\mathrm{Na}_{2} \mathrm{H}_{2} \mathrm{P}_{2} \mathrm{O}_{7}$. Environmental Technology, Vol. 38, 2305e2313. https://doi.org/10.1080/09593330.2016.1257658 
20. Paulauskas V., Zaleckas E., Karnaukh O. Biodegradable chelants for heavy metal removal from sludge and soil-sludge mixtures. Rural development 2019: Research and Innovation for Bioeconomy, pp. 1-6. https://doi.org/10.15544/RD.2019.059

21. Praspaliauskas M., Pedišius N. 2017. A review of sludge characteristics in Lithuania's wastewater treatment plants and perspectives of its usage in thermal processes. Renewable and Sustainable Energy Reviews, Vol. 67, pp. 899-907. https://doi.org/10.1016/j.rser.2016.09.041

22. Renella G., Landi L.L., Nannipieri P. 2004. Degradation of low molecular weight organic acids complexed with heavy metals in soil. Geoderma, Vol. 122, pp. 311-315. https://doi.org/10.1016/j.geoderma.2004.01.018

23. Ritschel J. 2003. Extraction of heavy metals from soil with selected biodegradable complexing agents. Diploma thesis. $106 \mathrm{p}$.

24. Schowanek D., Feijtel T. C. J., Perkins C. M., Hartman F. A., Federle T. W., Larson R. J. 1997. Biodegradation of [S,S], [R,R] and mixed stereoisomers of ethylene diamine disuccinic acid (EDDS), a transition metal chelator. Chemosphere, Vol. 34, pp. 2375-2391. https://doi.org/10.1016/S0045-6535(97)00082-9

25. State Waste Management Plan for 2014-2020 (LR). 2014, Vilnius. (In Lithuanian).

26. Suanon F., Sun Q., Dimon B., Mama D., Yu C. 2016. Heavy metal removal from sludge with organic chelators: comparative study of N, Nebis (carboxymethyl) glutamic acid and citric acid. Journal of Environmental Management, Vol. 166, pp. $341-347$. https://doi.org/10.1016/j.jenvman.2015.10.035

27. Sun B., Zhao F.J., Lombi E., Mcgrath S.P. 2001. Leaching of heavy metals from contaminated soils using EDTA. Environmental Pollution, Vol. 113, pp. 111-120. https://doi.org/10.1016/S0269-7491(00)00176-7

28. Takahashi R., Fujimoto N., Suzuki M., Endo T. 1997. Biodegradabilities of ethylenediamine-N, N-disuccunic acid (EDDS) and other chelating agents. Bioscience, Biotechnology, and Biochemistry, Vol. 61, pp. 1957-1959. https://doi.org/10.1271/bbb.61.1957

29. Yuan S., Xi Z., Jiang Y., Wan J., Wu C., Zheng Z., Lu X. 2007. Desorption of copper and cadmium from soils enhanced by organic acids. Chemosphere, Vol. 68, pp. 1289-1297. https://doi.org/10.1016/j.chemosphere.2007.01.046

30. Zaleckas E., Paulauskas V., Dainiene R. 2007. Extraction of $\mathrm{Cu}$ from sewage sludge using organic acids. Rural development, p. 252-256.

31. Zhang W. H., Lo I. M. C. 2006. EDTA-enhanced soil washing for remediation of $\mathrm{Pb}$ - or/and Zn-contaminated soils. Journal of Environmental Engineering, Vol. 132, pp. 1282-1288. https://doi.org/10.1061/(ASCE)0733-9372(2006)132:10(1282) 